\title{
Combined Atezolizumab and Chemotherapy for a Patient With Double Primary Cancers
}

\author{
SHINICHIRO OKAUCHI, YUIKA SASATANI, GEN OHARA, KATSUNORI KAGOHASHI and HIROAKI SATOH \\ Division of Respiratory Medicine, Mito Medical Center, University of Tsukuba, Mito, Japan
}

\begin{abstract}
Background: Immune checkpoint inhibitors are indicated for non-small cell lung cancer (NSCLC) and head and neck cancer, and combined treatment of immune checkpoint inhibitor and chemotherapy has recently been carried out in patients with NSCLC. However, there is no established standard therapy for synchronous locally advanced or metastatic cancers of lung and nasopharynx. Case Report: We report a case of a metastatic lung adenocarcinoma and locally advanced epipharyngeal carcinoma successfully treated with chemotherapy and immune checkpoint inhibitor, paclitaxel, carboplatin, bevacizumab and atezolizumab. The tumor proportion score of programmed death ligand 1 was $5-10 \%$ and $70-80 \%$ for metastatic lung adenocarcinoma and locally advanced epipharyngeal carcinoma, respectively. Shrinkage of both carcinomas was confirmed, and the treatment effect was judged to be a partial response. Conclusion: This was the first patient who was treated with this combination treatment. Our clinical experience suggests that this treatment could be one of the options for patients with these advanced cancers and an overall good clinical condition.
\end{abstract}

Lung cancer is one of the most common malignancies, which, in some cases, may develop synchronously with another malignant disease $(1,2)$. Head and neck cancer is among the synchronously detected malignant diseases that can be diagnosed during the workup of primary lung cancer $(3,4)$. In contrast, lung cancer can incidentally be found during the workup of primary head and neck cancer. Etiologically, it is generally accepted that cigarette smoking plays an important

This article is freely accessible online.

Correspondence to: Hiroaki Satoh, MD, Division of Respiratory Medicine, Mito Medical Center, University of Tsukuba, Miya-machi 3-2-7, Mito-city, Ibaraki, 310-0015, Japan. Tel: +81 292312371, Fax: +81 292215137, e-mail: hirosato0809@yahoo.co.jp

Key Words: Atezolizumab, chemotherapy, lung adenocarcinoma, epipharyngeal carcinoma. role in the carcinogenesis of both cancers (5). Previous casecontrol studies have shown that smoking is an important cause of lung cancer as well as head and neck cancers $(1,2)$. In both cancers, surgery is the preferred treatment option if tumours can be resected. For some patients, radiation therapy is also an option. However, systemic therapy is the main treatment for patients with locally advanced or metastatic disease. Immune checkpoint inhibitors have now been one of the main therapeutic drugs for both cancers $(6,7)$. Recently, in nonsmall cell lung cancer (NSCLC), combined treatment of immune checkpoint inhibitors and chemotherapy has become possible $(8,9)$. Treatment with immune checkpoint inhibitors for patients with double primary cancers including lung cancer has been reported in two patients $(10,11)$. However, there is no established standard therapy for synchronous locally advanced or metastatic cancers of lung and nasopharynx.

Here, we describe a case with metastatic lung adenocarcinoma and locally advanced epipharyngeal carcinoma treated with chemotherapy and immune checkpoint inhibitor. Both tumors responded well to the therapy. This unique case report demonstrates that synchronous double primary cancers including lung cancer may be effectively treated with this therapy.

\section{Case Report}

A 78-year-old man presented to our hospital with a swelling and pain in the right neck over the past 2 months. He was a previous smoker of 53 packs per year. Physical examination was unremarkable except for painful cervical swelling. The Eastern Cooperative Oncology Group (ECOG) performance status (PS) score was 1 . Computed tomography (CT) showed thickening in the right epipharyngeal wall and lymphadenopathy in the right neck (Figure 1). Biopsy specimens obtained from the cervical lymph nodes and the nasopharyngeal lesion revealed an epipharyngeal squamous cell carcinoma. Clinical stage of the epipharyngeal squamous cell carcinoma was T1N2bM1 stage IV. The tumor proportion score (TPS) of PD-L1 was 70-80\%. During the workup of the head and neck cancer, chest CT revealed a nodule measuring $18 \mathrm{~mm}$ in diameter in the upper lobe of the left lung (Figure 2) with lymph node swelling in 

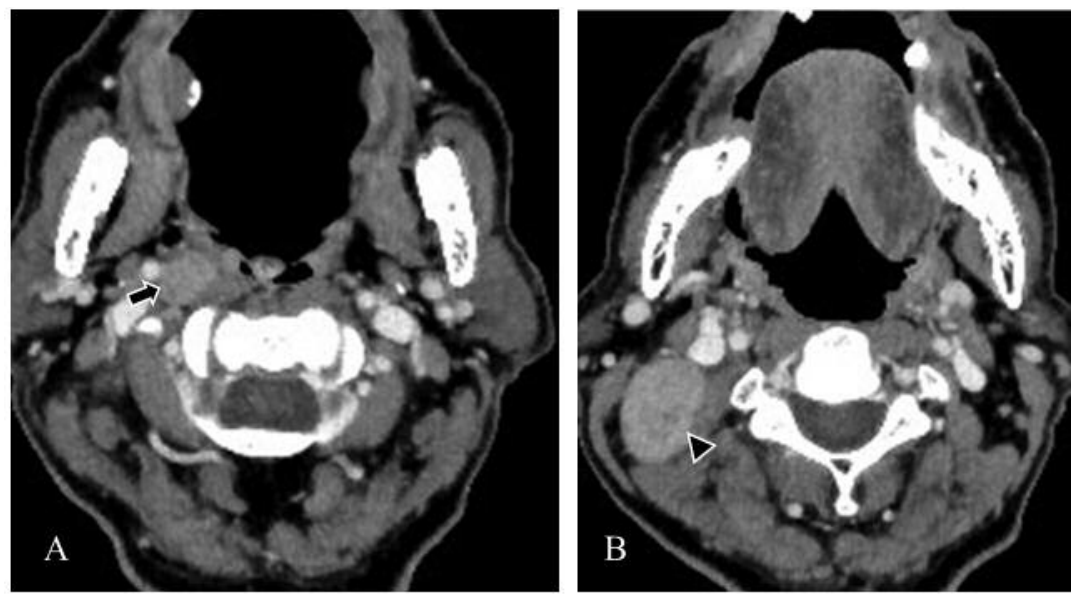

Figure 1. Computed tomography (CT) taken up on admission showed thickening in the right epipharyngeal wall (A) (arrow) and lymph node in the right neck (B) (arrow head).

both mediastinum. Transbrochial biopsy specimens revealed adenocarcinoma. TPS of PD-L1 was 5-10\%. Bone metastases were detected in spines and ribs. The patient was diagnosed as having Tb1N3 M1c stage IVB lung adenocarcinoma. Although the patient was 78-years old, PS was good (ECOG PS 1) and the patient and his family wished to receive active therapy. Therefore, taking into consideration his clinical condition (his age and general condition) the following treatment was planned and initiated, according to the IMpower150 study regimen (9): 6 courses of combination therapy with paclitaxel $\left(175 \mathrm{mg} / \mathrm{m}^{2}\right.$, day 1), carboplatin (area under the concentration-time curve of $5 \mathrm{mg}$ per $\mathrm{ml}$ per min, day 1$)$, bevacizumab $(15 \mathrm{mg} / \mathrm{kg}$, day 1$)$ and atezolizumab (1200 mg, day 1$)$ every 4 weeks, followed by maintenance therapy with atezolizumab (1200 mg, day 1) and bevacizumab (15 mg/kg, day 1$)$ every 4 weeks. A CT scan taken a month after the first course of therapy revealed regression of both cancers, which was evaluated as partial response (PR) (Figures 3 and 4). The patient developed a grade 2 skin rash, according to the National Cancer Institute Toxicity Criteria (2013 version). Treatment with the combination has been continued at the outpatient clinic, without any signs of tumor progression 7 months after the initiation of therapy.

\section{Discussion}

In the recent years, groundbreaking progress in cancer immunotherapy has revolutionized the field of oncology with unprecedented survival rates. This therapy has changed the treatment of several cancers including melanoma, NSCLC, urothelial and renal cell cancers, and head and neck cancers (12, 13). The possibility of surgical treatment is considered first if resection can be performed for head and neck cancer or lung cancer. Radiation therapy is also the main treatment for some head and neck cancers. If patients have metastatic disease, in

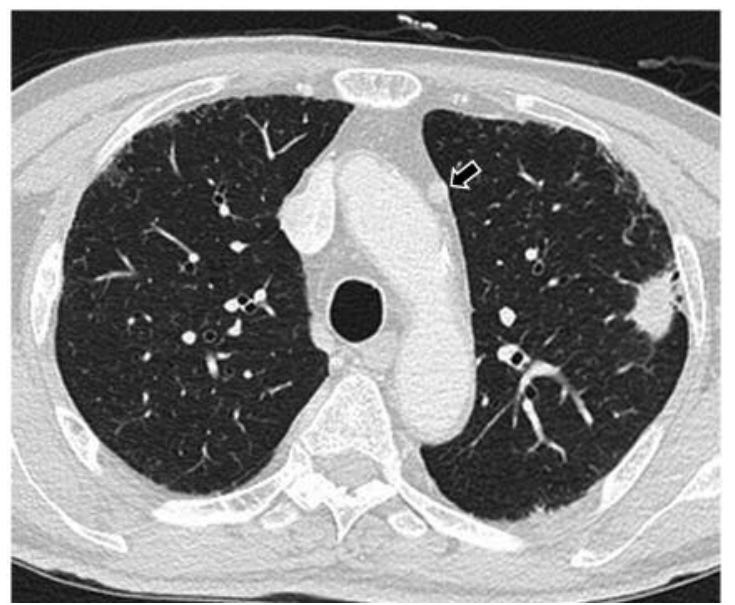

Figure 2. Chest CT taken up on admission showed a nodule of $18 \mathrm{~mm}$ in diameter in the left lung and mediastinal lymph node swelling (arrow).

general, the main treatment is systemic therapy such as chemotherapy. Immunotherapy has also become an option for these cancers $(6,7)$. For patients with head and neck cancer, immune checkpoint inhibitors, nivolumab and pembrolizumab, have been tested in randomized trials $(12,13)$. Atezolizumab is an anti-PD-L1 antibody administered in patients with NSCLC (14). As for this immune checkpoint inhibitor, improvement in the response rate and prolongation of PFS have been confirmed when combined with chemotherapy (15). The combination of an immune checkpoint inhibitor and chemotherapy has recently been indicated for NSCLC patients $(10,11)$.

There have only been few reports on immune checkpoint inhibitors being administered to double primary cancers including lung cancer $(16,17)$. One patient had synchronous 

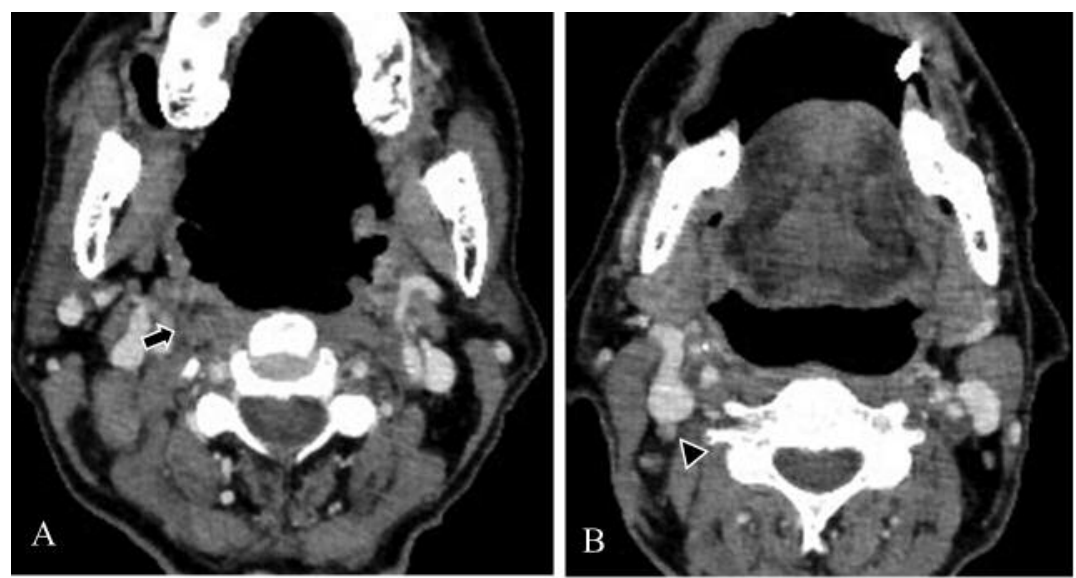

Figure 3. A CT scan taken a month after the first course of therapy revealed regression of the primary lesion of epipharyngeal carcinoma (A) (arrow) and lymph node in the right neck (B) (arrow head).

squamous cell lung cancer and colon cancer, which were treated with pembrolizumab (16). This treatment resulted in lung cancer shrinkage, and allowed colon cancer excision, confirming histological effects (16). Immune checkpoint therapy in two other patients has been reported by Yamada et al. (17). According to this report, these patients had double primary cancers, which were treated with pembrolizumab. In one of these patients, shrinkage of lung cancer was obtained, but no therapeutic effect was observed in comorbid bladder cancer. In the other case, no reduction in lung cancer was obtained, but a treatment effect on gastric cancer was achieved (17). For synchronous locally advanced or metastatic cancers of lung and nasopharynx, however, there is no established standard therapy. To the best of our knowledge, there are no reports of the combined use of immune checkpoints and chemotherapy in patients with double primary cancers including lung cancer. Our patient was a fit elder with a good performance status, and he expected the treatment to be more effective even if adverse events might occur. The patient had locally advanced epipharyngeal carcinoma, but he had no functional impairment such as difficulties in swallowing and articulation. The patient's prognosis was defined by the lung cancer rather than the head and neck cancer. Therefore, the combination treatment with immune checkpoint inhibitors and chemotherapeutic drugs for lung cancer was selected. However, considering the histological type of head and neck cancer, atezolizumab in combination with bevacizumab, paclitaxel, and carboplatin was selected for the first-line treatment of the patient rather than pemetrexed and pembrolizumab.

There have been many reports on the treatment of synchronous lung and epipharyngeal cancers that share a common carcinogenic mechanism $(18,19)$. However, this

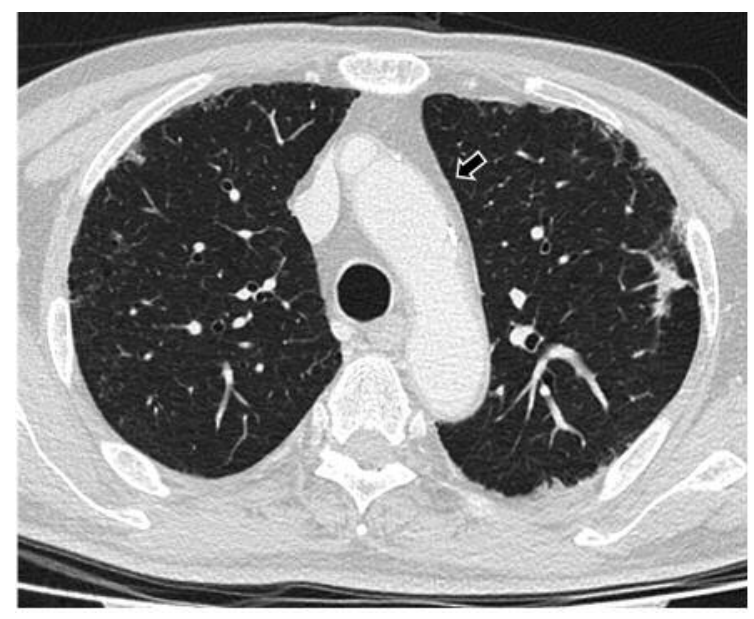

Figure 4. Chest CT scan taken a month after the first course of therapy revealed regression of the primary lesion of lung cancer and disappearance of mediastinal lymph node (arrow).

was the first patient with these two cancers who was treated with a combination of immune checkpoint inhibitors and chemotherapeutic drugs. Our clinical experience suggests that this treatment could be one of the options for patients with these advanced cancers and a generally good clinical condition.

\section{Conflicts of Interest}

The Authors declare no conflicts of interest regarding this study.

\section{Authors' Contributions}

SO, YS, GO: Collected the clinical data; KK, HS: wrote the manuscript. 


\section{Acknowledgements}

This research did not receive any specific grant from funding agencies in the public, commercial, or not-for-profit sectors.

\section{References}

1 Liu YY, Chen YM, Yen SH, Tsai CM and Perng RP: Multiple primary malignancies involving lung cancer-clinical characteristics and prognosis. Lung Cancer 35(2): 189-194, 2002. PMID: 11804692.

2 Kuriakose MA, Loree TR, Rubenfeld A, Anderson TM, Datta RV, Hill H, Rigual NR, Orner J, Singh A and Hicks WL Jr.: Simultaneously presenting upper aerodigestive and lung cancer: A diagnostic and treatment dilemma. Laryngoscope 112(1): 120123, 2002. PMID: 11802049.

3 Jeon SY, Ahn SH, Kim CH, Lim SM, Koh JS and Lee JC: Esophageal and laryngeal cancer incidentally found on [18F]fluorodeoxyglucose positron emission tomography/computed tomography during the staging workup for lung cancer. Clin Lung Cancer 9(4): 230-231, 2008. PMID: 18650172. DOI: 10.3816/ CLC.2008.n.035

4 Yigit O, Taskin U, Demir A and Behzatoglu K: Incidentally diagnosed simultaneous second primary tumor of the sphenoid sinus in a patient with lung cancer. J Craniofac Surg 20(6): 2175-2177, 2009. PMID: 19884834. DOI: 10.1097/SCS.0b013e3181bf03a3

5 Kuper H, Boffetta P and Adami HO: Tobacco use and cancer causation: association by tumour type. J Intern Med 252(3): 206224, 2002. PMID: 12270001.

6 Saada-Bouzid E, Peyrade F and Guigay J: Immunotherapy in recurrent and or metastatic squamous cell carcinoma of the head and neck. Curr Opin Oncol 31(3): 146-151, 2019. PMID: 30893149. DOI: $10.1097 /$ CCO.0000000000000536

7 Schvartsman G, Ferrarotto R and Massarelli E: Checkpoint inhibitors in lung cancer: latest developments and clinical potential. Ther Adv Med Oncol 8(6): 460-473, 2016. PMID: 27800034. DOI: $10.1177 / 1758834016661164$

8 Gandhi L, Rodríguez-Abreu D, Gadgeel S, Esteban E, Felip E, De Angelis F, Domine M, Clingan P, Hochmair MJ, Powell SF, Cheng SY, Bischoff HG, Peled N, Grossi F, Jennens RR, Reck M, Hui R, Garon EB, Boyer M, Rubio-Viqueira B, Novello S, Kurata T, Gray JE, Vida J, Wei Z, Yang J, Raftopoulos H, Pietanza MC, Garassino MC and KEYNOTE-189 Investigators: Pembrolizumab plus chemotherapy in metastatic non-small-cell lung cancer. N Engl J Med 378(22): 2078-2092, 2018. PMID: 29658856. DOI: $10.1056 /$ NEJMoa 1801005

9 Socinski MA, Jotte RM, Cappuzzo F, Orlandi F, Stroyakovskiy D, Nogami N, Rodríguez-Abreu D, Moro-Sibilot D, Thomas CA, Barlesi F, Finley G, Kelsch C, Lee A, Coleman S, Deng Y, Shen Y, Kowanetz M, Lopez-Chavez A, Sandler A, Reck M and IMpower150 Study Group: Atezolizumab for first-line treatment of metastatic nonsquamous NSCLC. N Engl J Med 378(24): 22882301, 2018. PMID: 29863955. DOI: 10.1056/NEJMoa1716948

10 Wang C, Kulkarni P and Salgia R: combined checkpoint inhibition and chemotherapy: New era of 1st-line treatment for non-small-cell lung cancer. Mol Ther Oncolytics 13: 1-6, 2019. PMID: 30976658. DOI: 10.1016/j.omto.2019.02.001

11 Weinberg F and Gadgeel S: Combination pembrolizumab plus chemotherapy: a new standard of care for patients with advanced non-small-cell lung cancer. Lung Cancer 10: 47-56, 2019. PMID: 31239797. DOI: 10.2147/LCTT.S176391
12 Harrington KJ, Ferris RL, Blumenschein G Jr, Colevas AD, Fayette J, Licitra L, Kasper S, Even C, Vokes EE, Worden F, Saba NF, Kiyota N, Haddad R, Tahara M, Grünwald V, Shaw JW, Monga M, Lynch M, Taylor F, DeRosa M, Morrissey L, Cocks K, Gillison ML and Guigay J: Nivolumab versus standard, single-agent therapy of investigator's choice in recurrent or metastatic squamous cell carcinoma of the head and neck (CheckMate 141): health-related quality-of-life results from a randomised, phase 3 trial. Lancet Oncol 18(8): 1104-1115, 2017. PMID: 28651929. DOI: 10.1016/S1470-2045(17)30421-7

13 Cohen EEW, Soulières D, Le Tourneau C, Dinis J, Licitra L, Ahn MJ, Soria A, Machiels JP, Mach N, Mehra R, Burtness B, Zhang P, Cheng J, Swaby RF and Harrington KJ; KEYNOTE040 investigators: Pembrolizumab versus methotrexate, docetaxel, or cetuximab for recurrent or metastatic head-andneck squamous cell carcinoma (KEYNOTE-040): a randomised, open-label, phase 3 study. Lancet 393(10167): 156-167, 2019. PMID: 30509740. DOI: 10.1016/S0140-6736(18)31999-8

14 Vansteenkiste J, Wauters E, Park K, Rittmeyer A, Sandler A and Spira A: Prospects and progress of atezolizumab in non-small cell lung cancer. Expert Opin Biol Ther 17(6): 781-789, 2017. PMID: 28335643. DOI: 10.1080/14712598.2017.1309389

15 Rittmeyer A, Barlesi F, Waterkamp D, Park K, Ciardiello F, von Pawel J, Gadgeel SM, Hida T, Kowalski DM, Dols MC, Cortinovis DL, Leach J, Polikoff J, Barrios C, Kabbinavar F, Frontera OA, De Marinis F, Turna H, Lee JS, Ballinger M, Kowanetz M, He P, Chen DS, Sandler A and Gandara DR and OAK Study Group: Atezolizumab versus docetaxel in patients with previously treated non-small-cell lung cancer (OAK): a phase 3, open-label, multicentre randomised controlled trial. Lancet 389(10066): 255-265, 2017. PMID: 27979383. DOI: 10.1016/S0140-6736(16)32517-X

16 Nozawa Y, Oka Y, Oosugi J and Takemura S: Immunotherapy for pulmonary squamous cell carcinoma and colon carcinoma with pembrolizumab: A case report. Medicine (Baltimore) 97(19): e0718, 2018. PMID: 29742733. DOI: 10.1097/MD.0000000000010718

17 Yamada H, Hida N, Satoh H, Yamagishi T, Hiroshima Y, Yoshii $\mathrm{S}$, Saito $\mathrm{T}$ and Hizawa N: Improved outcomes with pembrolizumab treatment in two cases of double cancer including nonsmall-cell lung cancer. Anticancer Drugs 30(1): 105-109, 2019. PMID: 30074503. DOI: 10.1097/CAD.0000000000000677

18 Tsao AS, Scagliotti GV, Bunn PA Jr., Carbone DP, Warren GW, Bai C, de Koning HJ, Yousaf-Khan AU, McWilliams A, Tsao MS, Adusumilli PS, Rami-Porta R, Asamura H, Van Schil PE, Darling GE, Ramalingam SS, Gomez DR, Rosenzweig KE, Zimmermann S, Peters S, Ignatius Ou SH, Reungwetwattana T, Jänne PA, Mok TS, Wakelee HA, Pirker R, Mazières J, Brahmer JR, Zhou Y, Herbst RS, Papadimitrakopoulou VA, Redman MW, Wynes MW, Gandara DR, Kelly RJ, Hirsch FR and Pass HI: Scientific Advances in Lung Cancer 2015. J Thorac Oncol 11(5): 613-638, 2016. PMID: 27013409. DOI: 10.1016/j.jtho.2016.03.012

19 Polo V, Pasello G, Frega S, Favaretto A, Koussis H, Conte P and Bonanno L: Squamous cell carcinomas of the lung and of the head and neck: new insights on molecular characterization. Oncotarget 7(18): 25050-250563, 2016. PMID: 26933818. DOI: 10.18632/oncotarget.7732

Received August 31, 2019 Revised September 24, 2019 Accepted September 27, 2019 